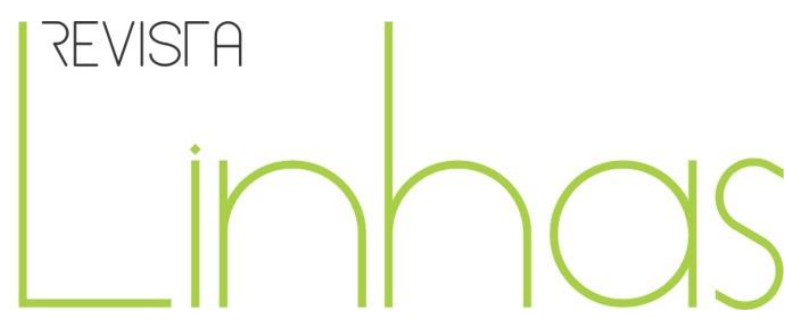

\title{
A Biblioteca Pública do Maranhão como espaço de sociabilidade na Primeira República (1898-1902)
}

\section{Resumo}

Estudo sobre a Biblioteca Pública do Maranhão como uma instituição promotora de práticas culturais socialmente compartilhadas por públicos distintos na Primeira República. Objetiva investigar as principais estratégias criadas pelo diretor desta Biblioteca visando promover a sociabilidade entre os diferentes públicos frequentadores desta instituição cultural. A pesquisa se caracteriza como histórica, pautada no arcabouço teórico e metodológico da História cultural. A compreensão da categoria teórica "sociabilidade" está centrada nas análises de Simmel (2006) e sociabilidade na biblioteca, Grogan (2001). A pesquisa documental, foi amparada nas análises do Relatório de Antônio Lobo, de 1900, 1901; os Relatórios encaminhados ao governador do Maranhão em 1902. Para a contextualização do período histórico, recorre-se a autores maranhenses como Viveiros (1960), Meireles (2011), Moraes (1973) e para a contextualização da Biblioteca Pública do Maranhão no período republicano utilizam-se os estudos de Silva e Castro (2012) e Moraes (1973). Como resultados de pesquisa, pode-se apontar que Antônio Lobo apresentava a Biblioteca Pública como um bem cultural público e visando dar visibilidade à Biblioteca, bem como, às suas próprias ações, cria e adapta espaços e eventos, a exemplo da sala de leitura para o público feminino; sala de leitura infantil; galeria de arte e seção de autógrafo. Por fim, constata-se que os empreendimentos de Lobo favorecem o crescimento e visibilidade da biblioteca, incentivando a aproximação, as conversas espontâneas e as relações antes consideradas improváveis de serem mantidas em um espaço público.

Palavras-chave: Biblioteca Pública do Maranhão (MA). Espaço Público de leitura. Sociabilidade. Primeira República (Biblioteca Pública).

\section{Diana Rocha da Silva}

Universidade Estadual Paulista Júlio de Mesquita - UNESP Araraquara/SP - Brasil rocha146@hotmail.com

\section{Para citar este artigo:}

SILVA, Diana Rocha da. A Biblioteca Pública do Maranhão como espaço de sociabilidade na Primeira República (1898-1902). Revista Linhas. Florianópolis, v. 21, n. 47, p. 264-289, set./dez. 2020. 


\title{
The Maranhão Public Library as a space of sociability in the Brazilian First Republic Period (1898-1902)
}

\begin{abstract}
This study approaches how the Maranhão Public Library was an institution that during the Brazilian First Republic Period used to promote social practices shared by different publics. It aims to investigate the main strategies created by Antônio Lobo, the director of the library in that period, and how he promoted sociability among the different public who used to go to that cultural institution. The study characterizes as historical research based on cultural history methodological fundaments. The understanding of 'sociability' as a theoretical category is based on the studies of Simmel (2006) and Grogan (2001). The document analysis reviewed Antonio Lobo's report from 1900, 1901 and the reports written by the governor of Maranhão in 1902. Authors from Maranhão, such Viveiros (1960), Meireles (2011), and Moraes (1973) are used to contextualize the historical period, while the studies of Silva and Castro (2012) and Moraes (1973) are used to describe the Maranhão Public Library during the Republican Period. Major results point to the fact that Antônio Lobo promoted the Public Library as a public cultural asset and gained visibility for himself and the library. Also, he adapted the library to events and created spaces as examples of the female reading room; children reading room; an art gallery, and the autograph section. Those initiatives helped the growth of the library and increased its visibility, encouraging closeness, spontaneous conversations, and relationships previously considered unlikely to be maintained in a public space.
\end{abstract}

Keywords: The Maranhão Public Library. Public Reading spaces. Sociability. Brazilian First Republic Period (Public Library). 
Discutir acerca do conceito de sociabilidade na Biblioteca Pública do Maranhão na Primeira República, especificamente no período de 1898 a 1902, permite-me retomar, de forma mais aprofundada, uma temática que foi abordada em 2009, quando tive o prazer de continuar uma pesquisa em nível de graduação. A obra fez parte de uma coleção constituída por 20 livros publicados, editados, comercializados e distribuídos em diferentes locais de consumo do escrito-lido, ou seja, dos dispositivos culturais produzidos com o intuito de serem distribuídos, comercializados e dados a ler, independentemente do suporte, tipos de leitura ou sujeitos com as suas diferentes intencionalidades. Essa investigação se configurou como uma importante referência para os estudos sobre a história da Biblioteca Pública e serviu como repertório para aprofundamento mais específico de algumas temáticas, que, num primeiro momento, se mantiveram lacunares, como, por exemplo, a sociabilidade.

Nesse sentido, busco nesta apresentação destacar as estratégias criadas por Antônio Lobo para a criação, divulgação e uso dos espaços e serviços oferecidos na Biblioteca Pública do Maranhão durante o período de sua gestão. Suas estratégias favoreceram a constituição de um espaço de sociabilidade e de convivência mútua, capaz de promover a públicos distintos o interesse pela leitura, o apreço pela arte e cultura em geral, antes não comuns nesse espaço.

A pesquisa se caracteriza como histórica, pautada no arcabouço teórico e metodológico da História cultural. A compreensão da categoria teórica "sociabilidade" está centrada nas análises de Simmel (2006), portanto, busca-se compreender de que forma Lobo, a partir de suas ações, proporciona a aproximação entre os diferentes sujeitos que frequentam a Biblioteca Pública do Maranhão. Para a análises desses aspectos, priorizou-se a pesquisa documental, utilizando principalmente o Relatório de autoria de Antônio Lobo, de 1900, no qual ele apresenta as principais estratégias criadas e adaptadas com o fim de promover a socialidade; além desse documento, analisaram-se os Relatórios encaminhados ao governador do Maranhão em 1901 e 1902. Para a contextualização do período histórico, recorre-se a autores maranhenses como Viveiros 
(1960), Meireles (2011), Moraes (1973) e para a contextualização da Biblioteca Pública do Maranhão, utilizam-se os estudos de Silva e Castro (2012) e Moraes (1973).

Entende-se por sociabilidade a forma lúdica e relaxada de socialização, ou ainda as ações condicionadas como se fossem parte de um jogo (SIMMEL, 2006). A espontaneidade manifestada nas ações e atitudes dos sujeitos, geradas a partir das estratégias de Lobo - com a criação de seções específicas e direcionadas a públicos definidos -, dá forma e sentido às relações que vão sendo estabelecidas por meio do diálogo cotidiano, da indicação dos livros, dos comentários das obras de artes. Simmel (2006, p. 78) destaca que "na sociabilidade, a liberdade para formar relações e a adequação de outra expressão não obedecem a qualquer condicionamento concreto e de conteúdo mais profundo".

O lúdico, nesse caso, assemelha-se ao espontâneo, ao natural e ao não impositivo. Mesmo ao instituir no Regulamento da Biblioteca (MARANHÃO, 1834) práticas legais para sua frequência e seu uso, as formas de se apropriar dessas diretrizes são particulares, individualizadas, burladas em função das relações que se estabelecem e dos laços de associação que se mantêm. Esses laços, por sua vez, "são incessantemente feitos e desfeitos, para que então sejam refeitos" (SIMMEL, 2006, p. 17). Sobre esse aspecto, Grogan (2001, p. 71) também é pontual em dizer que as conversas mantidas despropositadamente contribuem para o processo de sociabilidade, principalmente aquelas que são mantidas nos momentos iniciais do encontro com o outro,

[...] - por exemplo, troca de amabilidade, comentários sobre o tempo, pergunta sobre o estado de saúde. Ainda que o significado exato das palavras empregadas seja bastante irrelevante, isso é mais do que conversar por conversar pois contribui para o processo de regulação e de interação. (GROGAN, 2001, p. 71)

O esforço para a apreensão do mundo social, como a sociabilidade na Biblioteca Pública do Maranhão na gestão de Antônio Lobo, requer uma organização por meio de esquemas de

classificações, divisões e delimitações que organizam a apreensão do mundo social como categorias fundamentais de percepção e de apreciação do real. Variáveis consoante as classes sociais ou os meios intelectuais, são produzidas pelas disposições estáveis e partilhadas, 
próprias do grupo. São estes esquemas intelectuais incorporados que criam as figuras graças as quais o presente pode adquirir sentido, o outro tornar-se inteligível e o espaço ser decifrado. (CHARTIER, 1988, p. 17)

Para isso, é necessário compreender quais práticas eram diariamente encenadas na Biblioteca Pública do Maranhão, isto é, observar os gestos, as atitudes, as conversas e a sua reciprocidade para com o outro.

É nesse movimento que se pode definir os tipos de relações sociais que foram estabelecidas entre os diferentes personagens; as atitudes que foram manifestadas pelos sujeitos; e as interações que foram possíveis e imagináveis entre o que foi prescrito como norma de conduta e aquilo que foi praticado por determinado grupo.

Podemos deduzir que as mulheres tiveram uma atitude contida, discreta, compreendendo que o seu espaço era reservado e separado dos outros ambientes, em particular quando observamos os relatos de Antônio Lobo sobre a compra de objetos, a formação de acervos específicos e as constantes propagandas de convite às mulheres e às crianças para que frequentassem a biblioteca. Nesse viés, os principais questionamentos a serem respondidos são os seguintes: quais são as estratégias criadas por Antônio Lobo para promover a sociabilidade entre os diferentes públicos na Biblioteca? Que tipo de instrumentos são pensados e adquiridos para que esse espaço possa ser ocupado com mais naturalidade e fluidez? Que tipos de atitudes são encenadas pelas mulheres, crianças e adultos que, ao serem constantemente compartilhados, solidificam-se?

Ricoeur (1988), ao mencionar como surgem as verdades, analisa-as por meio de um processo que nasce no cotidiano social, nas relações, em que as ideias e informações, ao serem cristalizadas, transformam-se em "verdades" ou representam uma. Essas ideias solidificadas, estáveis e invariantes, possibilitam a compreensão da sociabilidade nos espaços da Biblioteca Pública do Maranhão durante a gestão de Antônio Lobo, já que não se pode conhecer a sociedade a partir de fenômenos isolados, individuais, mas pela reciprocidade que os sujeitos exercem uns com os outros (SIMMEL, 2006). 


\section{Um lugar público para a leitura}

A criação de espaços de sociabilidade públicos passa a ser incentivada na cidade de São Luís a partir do século XIX, época que coincide com a vinda da família Real para o Brasil, quando se investiu na criação de bibliotecas, jardins, teatros e museus, dentre outros lugares. Esses ambientes eram utilizados para transmitir ou impor algum tipo de sociabilidade manifesta nos ideários da cultura portuguesa em terras coloniais. Paiva (1987) e Saviani (2004) também alertam que com a vinda da família Real para o Brasil (1808), os investimentos se concentraram na construção de espaços de sociabilidade, a exemplo do Jardim Botânico, Museu Real, Biblioteca Nacional dentre outras repartições públicas que amenizassem o estado de atraso vivenciado no período Imperial, pelos resquícios do passado colonial. Nesse período eram discutidas a necessidade de criar Instituições culturais, entre as quais, as escolas, para atender a demanda educativa e cultural da chegada elite portuguesa.

Apesar de servir aos membros da elite, essas práticas, ao serem implantadas, passaram a ser compartilhadas por grupos periféricos à Coroa, que viam nessas possibilidades, a regeneração da alma por meio da educação e da cultura. Os estudos de Castro (2007) explicam que no período Imperial, D. João VI, em 1838, autorizou a criação do colégio D. Pedro II, na capital, Rio de Janeiro, e ampliou essa medida com a implantação dos Liceus nas demais províncias. Além disso, foram criadas escolas técnicas e instituições de ensino profissional. Esse empreendimento, segundo o autor, mantinha as crianças longe dos vícios, dos maus costumes e da vagabundagem.

A criação dos espaços de sociabilidade, ainda que restrita, ampliou-se com o tempo a partir de práticas culturais encenadas pelos sujeitos que frequentavam esses ambientes, tais como a leitura de um livro, jornal, revistas, ou mesmo conversas espontâneas sobre literatura, arte, história dentre outros assuntos que aproximassem emissor e receptor. Tais atitudes eram impulsionadas pelas indicações legalmente instituídas por meio do poder estadual, que também criava novos ritos, saberes e cultura. Essas ações tiveram início ainda na província, quando a Biblioteca Pública começou a assumir o seu lugar no cotidiano ludovicense, principalmente por ter sido criada através de uma subscrição popular. 
Oficialmente, a Biblioteca foi aberta ao público em 1831, ainda que ela tivesse sido requerida ao Presidente da província em 1826. Porém, por conta da falta de orçamento, sua institucionalização só foi possível em 1829, três anos depois do primeiro pedido.

O diretor da Biblioteca no relatório de 1900, ressaltava que nos países mais adiantados, no caso os EUA e alguns países da Europa, a área biblioteconômica ganhou força e empenho dos governantes, pois estes acreditavam que os assuntos voltados à inteligência eram prioritários. No Maranhão, no entanto, Lobo, nessa mesma época, questionava a postura do executivo, o qual considerava que o investimento na criação e na manutenção de bibliotecas era "malbaratar" os cofres do Estado, insinuando que era um desperdício de dinheiro qualquer gasto com a Biblioteca Pública, ainda mais num momento de crise econômica que caracterizou o Maranhão no final do século XIX, com a falência do modelo econômico, baseado na agricultura e na recém e ao mesmo tempo falida indústria (VIVEIROS, 1960). O diretor enfatizava que até mesmo os gastos com as medidas de asseio eram motivos para o descontentamento da administração pública. Assim, o diretor da biblioteca tinha um duplo desafio: o de convencer o Estado sobre a importância de se manter uma instituição voltada ao culto da letra, e ainda criar estratégias para estimular a frequência nessa repartição. Para convencer os governantes, era necessário "buscar os seus antecedentes históricos, esforçando-me por provar a sua utilidade, procurando mostrar como são estudadas e resolvidas nos países mais adiantados" (LOBO, 1900, p. 6).

Sobressaiu-se como fator que motivou a criação de uma Biblioteca Pública Provincial no Maranhão, a estreita relação comercial e cultural que se tinha com a Europa. Nota-se que o enriquecimento dos senhores latifundiários em decorrência da produção algodoeira propiciou-lhes o envio dos seus filhos para estudar na França, em Portugal, na Inglaterra. O contato com as instituições de cultura, entre elas os museus, teatros e bibliotecas, abria caminho para a civilidade e modernidade propagada nesse período. Sendo assim, os filhos da elite eram os futuros condes e viscondes, aqueles que viajavam para a Europa e voltavam para o Brasil divulgando o que tinham visto por lá.

São Luís passou a ser reconhecida pelo requinte de uma sociedade que, assim, tinha a seus olhos amostra viva do que lhes contavam os filhos que se haviam acostumados a mandar à Europa, [e que ao tentar imitar 
as práticas sociais do velho mundo] transformou-se na cidade, reconhecida pelas boas maneiras de seus hábitos. (MEIRELES, 2011, p. 258)

Aliado a esse envolvimento, em São Luís já havia um relativo crescimento das tipografias e do comércio de livros. Sobre esse aspecto, Castellanos explica que:

Esse movimento em torno do livro e da leitura culmina com a criação de vários espaços de sociabilidade utilizados para os encontros de leitores, lugares concretizados em bibliotecas, como a Pública provincial, a popular, a militar e o Gabinete português de leitura; a formação de associações como o grêmio literário, o Ateneu maranhense e a Onze de Agosto. (CASTELLANOS, 2010, p. 145)

Essa remodelagem social permitiu que os intelectuais maranhenses solicitassem a criação de uma biblioteca pública, lugar propício às discussões e debates, o compartilhamento de ideais, pensamentos e de assuntos de interesses diversos. Os intelectuais envolvidos nesse projeto ocupavam cargos estratégicos quer no executivo, legislativo ou judiciário, a exemplo do seu idealizador, o sr. Antônio Pedro Costa Ferreira, maranhense que exerceu o cargo de Deputado, foi Presidente da Província e Senador do Império. Costa Ferreira também era conhecido por Barão de Pindaré. Apesar de ter solicitado a criação da Biblioteca Pública do Maranhão, seu pedido foi recusado, haja vista que não havia disponibilidade financeira, como já dito acima, bem como, não existia um público numericamente expressivo, que impulsionasse ou pressionasse o Presidente da Província para a criação desse estabelecimento.

A dificuldade financeira vivenciada nesse período motivou o investimento de alguns indivíduos da sociedade ludovicense para a criação da Biblioteca Pública Provincial na década de 1820. Dessa forma, recorreu-se a uma subscrição popular, em que, além de doações em espécie, foram adquiridas algumas peças para compor o mobiliário e para a formação dos acervos. Algumas obras eram solicitadas na língua vernácula, porém Lobo recomendava o ensino nas escolas da língua francesa, preferencialmente, já que esta era falada em quase todos os países civilizados. Além disso, metade do acervo era composto por obras estrangeiras, adquiridas através de doações. 
De modo crítico é importante ressaltar que essa Biblioteca apresentava um caráter essencialmente elitista, tendo em vista os dispositivos de regulação das práticas empreendidas ou a realização no seu recinto. A denominação pública também se referia à administração do Estado, ao contrário do que deveria ser: um bem público, função que ficou num segundo plano.

O envolvimento específico de indivíduos da elite maranhense nem sempre se deu em virtude da preocupação com a educação ou com a situação cultural, mas como forma de serem reconhecidos como eruditos, sábios, homens cultos. Como se sabe, a biblioteca era vista como uma instituição fechada, privada, que atendia, em sua maioria, a uma pequena parcela da população, ou seja, aqueles que tinham algum tipo de influência na sociedade. Havia também o desejo de o Maranhão ser reconhecido como uma província desenvolvida, portadora de espaços de legibilidade cultural e que, segundo Borralho, podia ser medida "pelo nível educacional, pelo número de leitores, pela existência de instituições literárias, número de graduados em universidades europeias, bacharéis, livros publicados, tipografias, revistas entre outros elementos", uma vez que "o Código de sociabilidade define o nível de desenvolvimento espiritual”. Em complemento, conforme Borralho, era "a capacidade de absorver valores civilizacionais que Ihes possibilitassem a emancipação da tutela portuguesa" (BORRALHO, 2010, p. 90).

A Biblioteca passou a ser um lugar, um centro onde os indivíduos consumiam livros, jornais, magazines e outros artigos de cunho artístico e literário. Ao mesmo tempo, servia para demonstrar e reforçar a imagem de homens de bem, homens cultos, civilizados. Nela, se realizavam importantes eventos de enaltecimento da arte e da literatura, ponto de encontro de jornalistas, escritores, professores. Esses eram os principais públicos desse recinto.

O desejo dos indivíduos em se manterem unidos, frequentarem e estarem juntos no mesmo espaço surge, segundo Simmel,

sempre a partir de determinados impulsos ou da busca de certas finalidades. Instintos eróticos, interesses objetivos, impulsos religiosos, objetivos de defesa, ataque, jogo, conquista, ajuda, doutrinação e inúmeros outros fazem com que o ser humano entre, com os outros, em uma relação de convívio, de atuação com referência ao outro, com o 
outro e contra o outro, em um estado de correlação com os outros. Isto quer dizer que ele exerce efeito sobre os demais e também sofre efeitos por parte deles. (SIMMEL, 2006, p. 60)

Considero que um dos principais impulsos foi o interesse da elite maranhense em se aproximar dos ideais de civilidade e modernidade constantemente propagados na cultura europeia. Por certo, esse era o marco da divisa entre o mundo desenvolvido e o mundo atrasado, visão que se queria diminuir.

Com efeito, foi nesse clima de interesse elitista que a biblioteca foi criada. O seu acervo era formado por doações de livros, jornais e periódicos, além de uma coleção de numismática e uma seção reservada às artes plásticas. Tal cenário, por certo, introduziu uma nova cultura, ainda que reservada, preferencialmente pelo público masculino, trazendo ares de uma nova sociabilidade, propícia ao debate público, à consulta ao acervo e aos encontros de "Pessoas de Bem", como bem dizia Moraes (1973). Assim, frequentar a biblioteca era para aqueles que podiam se apresentar decentemente vestidos, ou para aqueles que sabiam ler, aspectos que eram excludentes, pois se sabe que no Maranhão a maioria da população era formada por escravos e a população alfabetizada não chegava a 20\% (VIVEIROS, 1960).

Os aspectos culturais da cidade também influenciaram a criação desse estabelecimento, já que o codinome de 'Atenas maranhense' exigia um lugar público, mesmo que o termo público se referisse a uma instituição pública, deixando o seu acesso ao público num segundo plano. Logo, os homens de letras queriam um lugar onde pudessem estabelecer relações no campo cultural, político e econômico, por meio de encontros não planejados, de conversas naturalmente iniciadas, de diálogo espontâneo, "surgido por impulso ou [por] oportunidade, [aquela que] se desenvolve, aprofunda-se, ameniza-se e termina, numa reunião social, fornecem uma miniatura do ideal de sociedade que se poderia chamar de liberdade de associação" (SIMMEL, 2006, p. 78).

Ademais, a sociedade foi estabelecida como um produto das manifestações de contato social, na medida em que "os indivíduos estão ligados uns aos outros pela influência mútua que exercem entre si, pela determinação recíproca que exercem uns sobre os outros" (SIMMEL, 2006, p. 17). Essas influências mútuas se efetivaram por meio 
da linguagem verbal e também por meio dos sinais não verbais transmitidos pelos diferentes produtores e consumidores de informação, nesse caso, as expressões faciais, os olhares, os gestos, as posturas (referindo-se aos movimentos corporais), os resmungos, os suspiros, o tom de voz, as pausas silenciosas (remetendo-as para a linguística), o toque, o vestuário, e outros aspectos ligados à aparência física que também servem para se comunicar (GROGAN, 2001, p. 101).

No Maranhão, existiam outros ambientes que tinham em comum a circulação do livro e a leitura. Como exemplo, podemos citar o Gabinete Português de Leitura, a Biblioteca Pública e algumas boticas que assumiram o papel de livrarias e se constituíam como espaços voltados aos encontros e à promoção de leitura, divulgação de obras e aos debates vários.

No Período Imperial, alguns indícios apontam para a sociabilidade estabelecida e legalmente aceita a partir da leitura do Regimento da Biblioteca, que não permitia a leitura oralizada, conversas de qualquer natureza em tom alto, passeio ou levantamento de alguma obra sem o auxílio do bibliotecário. Esse cenário me faz pensar sobre o tipo de relação que era estabelecida nesse recinto.

Aos visitantes eram franqueados papel e tinta, mas o empréstimo domiciliar não era permitido, aspecto que exigia ou impulsionava a ida à biblioteca para consulta ou consumo do escrito-lido. Essas também foram estratégias criadas pelo diretor para aumentar a assiduidade dos usuários. As restrições ao público também nos fazem deduzir que os leitores eram majoritariamente homens, já que a mulher não tinha livre acesso aos meios ou canais públicos sem a companhia dos pais, maridos ou responsáveis. A elas eram condicionadas regras de condutas típicas da época, práticas que vão se transformando com o aumento ou a inserção desse público no mundo escolar, tanto como alunas na Escola Normal ou de instituições religiosas, quanto como professoras de primeiras letras. Independente de um ou outro lugar, o importante foi que elas conquistaram outros espaços, além do âmbito doméstico, para se ocuparem. Esses espaços de sociabilidade são sustentados pela tese de que 
educar a mulher é garantir a educação completa dos filhos, porque é dela que a criança recebe, ao alvorecer da inteligência, as primeiras noções que lhe servirão de base para estudos futuros e conseguir o seu apoio à causa das bibliotecas públicas é assegurar o triunfo completo dessa instituição. (LOBO, 1900, p. 26)

A presença feminina nos espaços antes restritos, segundo Perrot (2005), foi uma tendência do século XIX, quando a perspectiva sonora foi mudada e o silêncio, que antes se mostrava como virtude, passou, aos poucos, a ser modificado pelo riso, pelas conversas, pelas opiniões. A ação civilizatória desse período tinha um duplo desafio: disseminar valores e normas de comportamento, bem como promover a união dos indivíduos em sociedade. Nesse caso, pode-se pensar de que forma as orientações referentes ao uso e às visitas à biblioteca foram apropriadas por personagens novos, pessoas que tinham o seu acesso dificultado por um obstáculo invisível, que barrava ou censurava a ida a esse estabelecimento e aos espaços públicos.

Então, como as mulheres e crianças agiam e se comportavam nesse ambiente adequado e preparado para elas? Um bom dia! Boa tarde! Com licença! Perdão! Os olhares desconfiados, ou não, geravam uma cordialidade que beneficiava e definia o convívio, a interação e a integração de diferentes públicos, sobretudo ao visitarem e ocuparem o mesmo recinto, pois a sociedade se definia a partir de diversas redes de interação entre os indivíduos, as quais eram impulsionadas por paixões e desejos que geram ações e reações (SIMMEL, 2006). Segundo Simmel (2006), as ações cordiais diminuíam as barreiras entre as classes sociais, beneficiavam a sociabilidade entre os homens, mulheres e crianças, pois "o forte e o extraordinário não somente se igualam aos mais fracos, como também agem como se fossem o mais valoroso e superior" (SIMMEL, 2006, p. 71).

Esse também foi um importante processo de sociabilidade que permitiu que, embora lentamente, o público feminino ocupasse ambientes antes reservados aos homens. Tais espaços, mesmo que rodeados por regras, olhares e censuras, permitiram à mulher uma proximidade com o mundo das letras, um consumo do livro como objeto cultural; um relacionamento ou convivência com a família e/ou instituições de ensino, de convivência em sociedade, em que se disseminavam concepções, práticas e atitudes que, ao serem constantemente repetidas, cristalizavam-se na sociedade. Para Ortiz (2000), a 
cada era e a cada período histórico, esses padrões são reconfigurados e novas sociabilidades são legitimadas.

Nesse ambiente, admitiam-se pessoas que estivessem decentemente vestidas, conforme o Regulamento da Biblioteca Pública de 1834, em seu artigo $5^{\circ}$. A circulação de pessoas também era contida, já que não era permitido passear e nem mesmo tratar sobre qualquer assunto em voz alta, mesmo que fosse de cunho científico. Esses fatos revelam a existência de um poder censório regulado por uma comissão formada pelo bibliotecário chefe, o qual, geralmente, era professor de primeiras letras nomeado pelo Presidente de Província; além do guarda mor e do contínuo, pessoa responsável pela biblioteca e diretamente, seja no controle do horário de abertura ou de encerramento das atividades, seja na vigilância das conversas, dos tons das falas, ou na recriminação de algum comportamento inoportuno). Aos poucos, a cultura das letras, das artes e o domínio do escrito foram se constituindo enquanto práticas que, ao serem partilhadas, ganharam uma visibilidade entre os ludovicenses, habilitando cenários propícios à cidadania. Foi nesse clima de prosperidade e engrandecimento que as instituições culturais ganharam força no Maranhão, como bibliotecas, museus, escolas, institutos e sociedades literárias.

Reportando-se ainda acerca do século XIX, o caráter excludente da biblioteca conseguiu afastar outras possíveis clientelas, que, de certa maneira, poderiam dar visibilidade a essa instituição pública, formada por crianças, senhoras e pessoas comuns. Esse fato foi determinante para que, em meados do século XIX, a Biblioteca tivesse o seu desempenho reduzido e os investimentos para o seu desenvolvimento também fossem perdendo espaço ou credibilidade perante o poder público e a sociedade ludovicense.

Sem as verbas disponíveis para a sua manutenção e asseio, a compra de novos títulos para a composição do acervo, o pagamento dos funcionários, a Biblioteca, em 1866, passou a ser administrada pelo Instituto Literário e, em 1872, ficou sob a custódia da Sociedade Onze de Agosto, percurso que culminou no seu declínio (VIVEIROS, 1960) até o ano de 1896. Nessa ocasião, os seus livros, por autorização do governo, foram atirados em fogueiras ou extraviados durante as sucessivas mudanças que a Biblioteca era obrigada a fazer. Essa tragédia foi contada por historiados como Jomar Moraes (1973) e Jerônimo de Viveiros (1960), especialmente quando se referiam ao triste fim da primeira Biblioteca criada em 1829. 
Sabendo dessa trajetória, Antônio Lobo, ao assumir a direção em 1898, dois anos após a sua recriação, que teve como diretor Ribeiro do Amaral, tratou de criar estratégias para a democratização desse espaço cultural.

\section{As estratégias de Antônio Lobo e os espaços de sociabilidade na Biblioteca Pública do Maranhão}

Personagem reconhecido em São Luís por seu forte envolvimento cultural, Antônio Lobo gerenciou a Biblioteca Pública do Maranhão durante o período de 1898 a 1910. Ao assumir cargos públicos e privados, como o de Secretário Geral da Instrução Pública, Diretor do Liceu maranhense, redator, jornalista, polígrafo, tradutor, escritor e professor, foi reconhecido pela sua atuação e engajamento também na área biblioteconômica, com a publicação do Relatório da Biblioteca Pública de 1900, no qual apresentou, de forma detalhada e bem fundamentada, os serviços realizados e os produtos informacionais oferecidos durante a sua gestão na Biblioteca Pública do Maranhão.

Profundo conhecedor das atividades biblioteconômicas existentes nas bibliotecas europeias, por meio da leitura de seus relatórios, na época publicados e disponibilizados às outras instituições congêneres, Lobo primou pelo seu reconhecimento pessoal perante à sociedade ludovicense, como um agente público e homem de letras, e se dedicou sobremaneira a essa constatação, propondo a organização e realização de atividades na Biblioteca Pública do Maranhão. O intuito era dar visibilidade à mesma, por meio de estratégias para a sua democratização, e, dessa forma, assegurar notoriedade a ele próprio, criando ou realizando projetos direcionados a sua equiparação às instituições similares, tanto nacionais quanto internacionais. Logo, aproximou-se dos interesses de públicos distintos, isto é, homens, mulheres, crianças, e visou a formação leitora, educativa e cultural da sociedade (SILVA; CASTRO, 2012). A biblioteca acabou por assumir um lugar de sociabilidade utilizado para encontro entre os amigos, para a leitura de jornais, revistas e livros. Gradativamente, também se tornou um local de "prosperidade e de bem estar, que os livros sempre proporcionam àqueles que nos procuram o convívio" (LOBO, 1900, p. 1). 
Como se pode observar, Lobo assumia uma posição de destaque, e por sua vez, criava ações, que aqui chamamos de estratégias, conforme a concepção de Certeau (2014, p. 96): “As estratégias são, portanto, ações que graças ao postulado de um lugar de poder [...] elaboram lugares teóricos (sistema e discursos totalizantes), capazes de articular um conjunto de lugares físicos onde as forças se distribuem". A posição de diretor assegurava a Lobo a liberdade de criar, a partir da sua visão e da própria experiência, eventos ou serviços que seriam consumidos pelos frequentadores (reais e potenciais) da Biblioteca Pública do Maranhão. É importante também salientar que ao mesmo tempo em que Lobo direcionava os eventos, os receptores, numa posição inversa, recepcionaram aquilo que lhes foi imposto, mas, nem sempre de forma neutra, passiva ou sem intenções. Essa recepção é mobilizada por meio de táticas de apropriação, ou seja, os indivíduos transitam pelas imposições a partir de intencionalidades próprias (CERTEAU, 2014).

Esses aspectos podem ser compreendidos quando Lobo, ao constatar a pouca frequência feminina determinada pelos usos e costumes da época, os quais à mulher eram reservados os cuidados com a casa, marido e os filhos, isto é, "adaptadas a suas tarefas naturais - esposas, mães, donas de casa [...]." (PERROT, 2005, p. 271), aos poucos foi se enfraquecendo, transformando-se a partir de posturas pessoais das mulheres, pais e sociedade em geral. Essas pessoas se envolviam e interagiam com novas práticas culturais, impulsionadas pelos desafios educacionais que exigiam novos saberes e novas vivências; com o econômico, que também desafiava a sociedade a assumir novos postos de trabalho; com o político, a partir de outras obrigações e outros posicionamentos que enfatizavam, principalmente, as obrigações do cidadão e os deveres com o Estado; e com o processo de inovação tecnológica, sobretudo no âmbito da moda, literatura, música, aspectos que mudam também a visão que se tem sobre o papel social das mulheres.

Esse público começou a se inserir no mundo das letras e a ocupar espaços antes restritos apenas aos homens. Com as ações de Antônio Lobo, fortaleceu-se o processo de sociabilidade das mulheres ludovicenses através da criação de uma Sala de Leitura exclusiva para elas. Esse lugar podia ser por elas ocupado com menos timidez, sem correrem o risco de sofrerem com a censura do marido, pais ou responsáveis, ou mesmo 
de outras senhoras que achassem um absurdo mulheres frequentarem o mesmo ambiente dos homens.

Para a época e lugar, Lobo foi considerado um visionário, em particular por ler relatórios de instituições congêneres sediadas na Europa e nos EUA, e por querer implantar os mesmos projetos em terras onde as mudanças culturais e sociais eram precoces. Apesar do Estado ter se tornado laico, livre e democrático, essas mudanças se efetivaram bem lentamente no cenário brasileiro.

Preocupando-se com a pouca frequência das mulheres, especialmente quando comparada à assiduidade do público ordinário, Lobo decidiu investir na aquisição de compêndios destinados ao imaginário feminino, livros e revistas que tratavam de moda, criação dos filhos, cuidados com a casa e com o marido, livros de receita e de costura. Obras como L'alimentation des nouveaus-nes, de Dr. Serverin Icard, e La femme la mere et l'efante, guide à L'usage des jeunes mères, de autoria de M. Augusta Weins, foram exemplos que indicavam os tipos de leitoras para os quais estavam sendo direcionados. No geral, essas mulheres mantinham algum contato com a língua francesa (LOBO, 1901; MARANHÃO, 1902).

De certo modo, esse fato também apontava que a cidade de São Luís queria ser reconhecida como capital fundada pelos franceses e, por isso, esforçava-se em reproduzir, nos usos e costumes, a cultura dessa terra, seja nos modos de se vestir e falar, seja na forma de se portar, isso falando da alta sociedade. Lima declara que:

O Maranhão viveu por muito tempo isolado do resto do Brasil, integrando um Estado autônomo e, mesmo depois da unificação das capitanias do Reino Unido do Brasil, conservou-se esquivo e reservado no antigo vício do culto à Europa e sua civilização. A corte para nós, e por muito tempo, foi a europeia, Lisboa, Paris e Londres. (LIMA, 1981, p. 137)

Lobo também tentou conquistar as mulheres por meio das leituras que faziam parte do cotidiano de mães, filhas e esposas. Logo, 
o acesso ao livro e à escrita, modo de comunicação distanciada e serpentina, capaz de enganar as clausuras e penetrar na intimidade mais bem guardada, de perturbar um imaginário sempre disposto as tentações do sonho, foi-lhes por muito tempo recusado, ou perniciosamente cedido, como uma porta entreaberta para o infinito do desejo. (PERROT, 2005, p. 10)

Essas leituras ainda podiam beneficiar os maridos, ensinando como a mulher podia ser uma boa dona de casa. Em sua maioria, as obras de língua francesa e inglesa eram adquiridas por meio de doações. A imagem da mulher era divulgada como um ser frágil, dócil, intocável, puro, características que faziam com que as famílias mantivessem as figuras femininas resguardadas, exaltando o papel a ser desempenhado de esposa e mãe. Isso também enfatizou o medo dos chefes de família em imaginar suas filhas como vítimas de ataques difamatórios, levando em consideração que no Maranhão, segundo Moraes (1973, p. 130), existiam, de forma incisiva, "os vícios da terra, com a mentira, a calúnia, e a infâmia, além do perjúrio e a difamação, o falso testemunho, a maledicência”. Acrescenta-se ainda que "era próprio do ludovicense falar mal da vida alheia", aspecto que não era restrito à região geográfica, mas típico de um tempo específico.

Sobre esse aspecto, Lobo explicou que, somente com paciência, perseverança e em longo prazo, poder-se-ia "vencer o triste prejuízo, entre nós reinantes de que a uma senhora não fica bem frequentar uma biblioteca pública [...].” (LOBO, 1900, p. 29). Abrantes (2004, p. 144) também esclarece a visão que se tinha da mulher no final do século XIX e início do XX:

Muitas famílias consideravam um absurdo mandar ensinar suas filhas a ler e escrever ou, dos que achavam que somente o ensino básico da leitura e da escrita era suficiente na educação de uma moça [...] a imagem feminina construída pela sociedade [...] apresentava as mulheres como seres amáveis, dóceis, frágeis, inferiores, submissas, sendo essas características naturais ao sexo feminino. Nesse imaginário social, exaltava-se a virgindade, o papel de esposa e mãe exemplares. (ABRANTES, 2004, p. 144)

Sabendo dessas características ou consciente desses costumes culturalmente compartilhados, além da proteção esmerada à mulher, Lobo criou um ambiente próprio, onde elas poderiam ter a sua imagem assegurada e livre dos "fuxicos" e dos "disse-me- 
disse" tão marcantes da época. Esse cenário, por sua vez, condicionava o comportamento do público. Ao visitarem a biblioteca, as mulheres apenas "folheavam um ou outro livro, tímidas, indecisas, sendo raro que alguém se entregasse a uma leitura mais demorada" (LOBO, 1900, p. 29). Por isso, era necessário criar um ambiente elegante, agradável, acolhedor, adequadamente estruturado para o recebimento e aceitação desse público.

E foi o que fiz, mandando, com a vossa autorização, preparar, ao lado do salão geral de leitura, um outro menor, reservado às senhoras, que procurei tornar o mais elegante e confortável possível. E tive a satisfação de verificar que não me enganei a esse meu modo de ver. A frequência feminina tem aumentado bastante e com muito mais resultado e espero que assim continuará, porque as senhoras maranhenses acabarão por convencer-se de que a biblioteca não foi criada só para os homens e de que, frequentando-a, acolhendo-a favoravelmente, não só retirarão para si grandes proveitos, mas prestarão um imenso e relevante serviço ao seu estado, garantindo com esse procedimento os destinos da instituição. (LOBO, 1900, p. 1)

Todos esses investimentos resultaram no aumento da frequência de ambos os sexos. Há de se pontuar que o público feminino teve um notório interesse em visitar a biblioteca e ver nesse espaço um pretexto para sair de casa e compartilhar outros mundos. Em janeiro de 1898, mês de reinauguração da Biblioteca, Antônio Lobo teve o prazer de receber entre os dias 25 e 31, 93 visitantes, dos quais 89 eram homens e quatro mulheres. Nesse período, segundo o relatório de 1999, não houve leitoras. No mês de março desse mesmo ano, o público feminino chegou ao seu máximo, contabilizando 28 visitas de um total de 489 frequentadores, dos quais doze se declararam leitoras. No ano seguinte (1999), o mês de dezembro teve um aumento de 108 mulheres, levando-se em consideração o mesmo mês do ano anterior, que teve apenas dez usuárias (1898); registra-se um crescimento de $1118 \%$. Tal número também se repete em julho desse mesmo ano. Nota-se ainda um bom índice de visitas desse público nos meses de setembro (74), outubro (73) e novembro (93) de 1899.

Outra ação de Antônio Lobo que resultou no aumento do público infantil foi a organização de um acervo exclusivo para as crianças. Os recursos destinados a esse fim podiam incentivar o gosto pelo escrito-lido, pelas pesquisas escolares, minimizando a carência de suportes informacionais (livros, revistas, jornais, dentre outros) disponíveis 
nas escolas e livrarias. Castellanos (2010, p. 149) explica que, com a expansão das escolas para ambos os sexos, "aflorou um maior interesse pelo livro e outros impressos, uma maior obrigação ou dedicação pela leitura e, portanto, um acréscimo de novos leitores".

Nesse ambiente, as crianças poderiam, com mais facilidade, fazer pesquisas sobre temáticas trabalhadas em sala de aula. Para tanto, Lobo contou com a ajuda de alguns professores, os quais contribuíram para que os resultados desse projeto fossem alcançados: o aumento da frequência do público infantil e os recursos informacionais existentes na biblioteca como suporte pedagógico.

Já me dirigi por ofício a cada um dos professores do Liceu, da Escola Normal, e do Curso do Comércio, pedindo-lhes que me indicassem os livros que reputavam melhores para o estudo da matéria que lecionam, a fim de adquiri-los para a biblioteca, pois o professor é um dos maiores aliados do bibliotecário, e assim, fazer com que os alunos aqui venham consultá-los. (LOBO, 1900, p. 66)

As vantagens vistas por Lobo aumentaram a frequência desse público e, ao mesmo tempo, despertaram outras preocupações, pois o espaço destinado a essas atividades já não era suficiente: “[...] proporções necessárias para comportar o incremento que se ia tendo [...], não havia mais espaço suficiente para a colocação de novas estantes que recebam os livros. Os quais já se acham em grande número sem as acomodações necessárias." (LOBO, 1900, p. 24).

O critério de escolha do local para a biblioteca correspondia às dimensões suficientes para conter as coleções. Quanto à construção de prédios, a ação voltou-se muito mais para o estilo arquitetônico, com a criação de edifícios suntuosos que priorizavam a beleza em detrimento da adequação, não importando se o imóvel era adequado ou não. O que interessava era se a construção chamava a atenção pela beleza e exuberância. Era esse entendimento que Lobo queria transmitir. No Maranhão, por exemplo, a biblioteca foi instalada num ambiente escuro, sem ventilação, em uma das salas do Convento do Carmo, onde começou a sua história. Nessa época, as dimensões não consideravam as outras práticas que poderiam ser empregadas nesse espaço. $O$ cuidado era com os possíveis roubos ou com a não devolução dos livros, o fogo, a 
umidade, o calor e o próprio tinteiro deixado à disposição dos consulentes. Todos esses aspectos eram inofensivos à guarda e à conservação das coleções.

Sobre isso, Lobo (1900) destacava que na construção de bibliotecas dois itens eram fundamentais: o espaço destinado às coleções deveria ser condizente e apropriado à conservação de futuros livros, bem como suficiente para as futuras ampliações. Se as bibliotecas deveriam ser o espaço necessário para o seu fim, Lobo requeria a mudança do prédio para um local adequado, onde pudesse realizar as demais atividades de cunho educacional, solicitação não aceita por conta do cenário econômico, marcado pela crise financeira.

Lobo também investiu na organização de um local exclusivo para exposições iconográficas, obras de arte que, ao serem expostas, poderiam ser apreciadas pelos diferentes públicos e incentivar a frequência de usuários na biblioteca. Esse setor, ao ser inaugurado, contou com um acervo adquirido pela doação de 20 fotogravuras, cada uma medindo $22 \times 28$ polegadas, dentre elas: Rudyard Kipling (quadro de P. Burne-Jones); Shakespeare lendo Macbeth na corte de Elisabeth (de autoria de Eduard End); Dante e Beatriz em Florença (quadro de Harry Holiday); Alfred, lord Tennyson (de G. F. Watts); Molière e a sua troupe de comediantes (de Gaston Melingue); Swift e Stella (quadro de M. J. Dicksee); o Encontro de Milyon com Andrew Marvell (quadro de G. H. Boughton); O primeiro encontro de Burns com Walter Scott (quadro de C. M. Hardie); Thomas Carlyle (quadro de J. M. Niel Whistler); Homero (quadro de P. Puvis de Chavannes) (LOBO, 1900, p. 105).

O que Lobo desejava era estreitar a relação entre a biblioteca, a escola e a sociedade, isto é, "estabelecer esses laços é tornar a existência de uma inteiramente dependente da outra e fazê-la finalmente agir como uma só força em prol da grande causa da educação popular" (LOBO, 1900, p. 22). Esse diretor também criou alguns projetos, que contaram com a participação ativa de ilustres personagens da nossa literatura maranhense.

Dos principais projetos de âmbito sociocultural que beneficiaram a biblioteca, dois receberam destaque. O primeiro projeto foi a Seção de autógrafos, inaugurada em 1898, com o objetivo de contribuir para a disseminação das obras de autores maranhenses interessados nessa divulgação. Domingos de Castro Perdigão doou os autógrafos 
“Princípios de música”, de Domingos Thomaz Vellez Perdigão, e "Poema Mais Mundo”, de Theophilo Braga, publicado no Rio de Janeiro por ocasião do $4^{\circ}$ Centenário do Brasil, e editado pelo Sr. Fran Paxeco, que também ofereceu à biblioteca o romance "Vera Cruz", de Coelho Neto.

O segundo projeto foi nomeado de Conferências públicas, quando, a partir do interesse do público, debatia-se alguma temática. Geralmente, era convidado um professor, escritor ou personalidade de certa influência na sociedade maranhense e que oportunizava o debate, a reflexão e o acesso à informação. As conferências públicas, de caráter essencialmente didático, eram realizadas em dias e horários previamente anunciados, no salão de leitura e voltadas para toda inteligência. Por esse motivo, era utilizada uma linguagem simples, clara, além de projeções luminosas com o uso de lanterna. Ao final, indicavam-se livros sobre o assunto que existiam na biblioteca. $O$ objetivo dessas Conferências era popularizar e chamar a atenção pública para a participação nesses eventos, além de atrair, auxiliar e guiar as pessoas para o aprofundamento dos assuntos apresentados durante as conferências. Esse projeto já havia se realizado em 1871 e 1872 na Escola Onze de Agosto, com o professor Antônio de Almeida e Ennes de Souza, cujo nome era Conversas Públicas. A primeira conversa teve como título "A Sociabilidade e o poder da associação", prefaciado por Antônio Lobo.

Todas essas ações tiveram uma franca aceitação por parte de diferentes públicos e se destacavam pelo aumento da frequência e pelo crescimento das doações de livros, quadros e outros instrumentos necessários à composição do acervo e manutenção da biblioteca. Nesse período, a biblioteca já funcionava regularmente, pois havia uma frequência considerável de leitores que encontravam quase todas as obras que procuravam. Segundo o diretor, prosseguia-se com êxito a organização dessa instituição, resultando no aumento da assiduidade e na satisfação dos usuários. Além disso, esse era o espaço considerado um dos mais poderosos elementos da cultura intelectual, base segura de toda a civilização e progresso (LOBO, 1900). 
Se os espaços são configurados a partir das práticas, consideramos que estas também estão alicerçadas nos lugares ambientados e adaptados para determinado fim. Podemos notar esse aspecto nas estratégias criadas por Antônio Lobo, especialmente quando diretor da Biblioteca Pública, ao criar seções ordenadas para sujeitos antes ausentes, como as mulheres e crianças.

Ao analisar a Sala de Leitura, que teve um ornamento singular, diferenciado dos outros ambientes já existentes no interior da Biblioteca, constato que Lobo conseguiu incentivar a frequência e a assiduidade do público feminino. Se essas ações, num primeiro momento, conseguiam atrair a atenção ou o interesse de poucas mulheres, em longo prazo também permitiram a ideia de um espaço destinado às senhoras, já que elas e a sociedade como um todo concebiam a biblioteca como um lugar propício à aquisição de informações úteis e que faziam parte do seu dia a dia. Além disso, no final do século XIX e início do XX, a mulher ganhou novas oportunidades, pois o foco do seu papel social mudou. Ela também passou a ser vista como a melhor educadora dos filhos, inserindo-se no campo profissional como aluna ou como professora de primeiras letras, aspecto que a própria sociedade admitiu como necessário, legitimando a ida de senhoras a essa instituição.

Pensar de que modo as mulheres se relacionavam nesse ambiente com outros personagens, os quais tipicamente ocupavam-se da leitura e da arte, no caso os homens de letras, é uma forma de refletir sobre os modos de comportamento dessa época, aquilo que era aceito como prática comum e aquilo que era censurado como prática inaceitável. Havia no ideário social do final do século XIX e início do XX uma generalização de que as mulheres não sabiam falar sobre assuntos alheios à casa, à criação dos filhos, à moda. Essa impressão também se justificou quando Lobo organizou coleções essencialmente formadas por temas de uso exclusivamente feminino, pensamento que aos poucos foi se enfraquecendo. Os temas mais recorrentes eram sobre a economia e política, os quais dominavam as rodas de conversas do público masculino. Nesse caso, considero que a mulher, ainda que frequentasse o mesmo ambiente dos homens, ficava restrita à sala de leitura, mantendo contato com as pessoas do mesmo gênero ou com os funcionários da biblioteca, geralmente homens. 
Considero ainda que até mesmo a cortesia era minada, já que não era costume as mulheres se dirigirem aos homens naturalmente, como se isso fizesse parte do cotidiano delas. Isso não quer dizer que, de uma forma ou de outra, utilizando-se de sutilezas, algumas mulheres marcaram presença na biblioteca, transitando por outros espaços, como, por exemplo, o acervo infantil, pois algumas professoras eram consultadas pelo diretor para a indicação de livros escolares. Outros espaços, aos poucos, também foram sendo explorados, como a Galeria de arte, as Conferências públicas e a Seção de autógrafos. Esses projetos oportunizaram que algumas senhoras mantivessem contato, ainda que distante e sob a supervisão atenta dos seus acompanhantes, no caso dos maridos, tutores, pais ou irmãos, com outros públicos. A presença das consulentes foi se incorporando como natural e o objetivo de Lobo se consagrou: tornar lícita a visita da mulher a uma biblioteca.

Também constatei que, ao criar e adequar acervos destinados ao público infantil, Lobo conseguiu contribuir para a disseminação do ensino público, já que havia pouca circulação de livros escolares à época. Com efeito, as crianças procuravam a biblioteca com um duplo sentido, tanto para ter acesso aos recursos informacionais indicados pela escola quanto para ter ao seu dispor livros de literatura, arte, enciclopédias e outros artigos, como mapas para complementar seus estudos. As solicitações se voltavam principalmente para a aquisição de acervos na língua portuguesa, língua acessível e mais abrangente para as crianças, já que elas não tinham noção da língua inglesa e francesa, dominantes no acervo nessa época.

A Biblioteca Pública do Maranhão definitivamente rompeu com o silêncio! Pensar nas turmas de crianças e adolescentes entrando, passeando, consumindo os suportes informacionais, interagindo com os funcionários e com o público da biblioteca me faz pensar em um novo momento para uma instituição que, até pouco tempo atrás, ocupavase essencialmente da organização e manutenção de livros. Projetos como esse tornam o dia a dia da biblioteca dinâmico. Ademais, o bibliotecário também passou a desempenhar outras competências que exigem certos atributos tipicamente esperados desse profissional ao tratar diretamente com o público, como a amabilidade, a simpatia, a cortesia. Nesse caso, a relação mantida com as crianças, embora fosse marcada por censuras e reprovações, como ao corrigir algum comportamento indevido (o falar alto ou 
a retirada de algum exemplar sem o auxílio dos funcionários), promovia uma interação que caracterizava e definia a sociabilidade mantida nesse espaço.

Os projetos criados por Lobo garantiram ainda uma sociabilidade entre os diferentes públicos, os quais tinham em comum o desejo de frequentar a biblioteca. Criar uma seção de autógrafos e um bate-papo com o autor oportunizava uma proximidade entre os leitores e o responsável intelectual das obras, bem como a discussão com maior profundidade sobre temas relevantes e de interesse geral. Nesses encontros, permitia-se manter uma conversa menos formal com o autor das obras: perguntas, dúvidas, comentários, opiniões, elogios, desconfianças e risos. Essas ações eram demonstradas pelo público presente e definiam o tipo e o grau de sociabilidade mantidos nesse espaço.

Considero, portanto, que as ideias de Antônio Lobo marcaram um novo tipo de interação social, responsável não apenas por tornar acessível a entrada de diferentes públicos na biblioteca, mas de nivelar crianças, jovens e adultos; isto é, deixar num mesmo patamar pessoas de diferentes idades, de diferentes níveis sociais, com diferentes perspectivas e motivações, caracterizando a biblioteca como um espaço público franqueado a todos, (respeitando, é claro, o momento histórico que, por sua própria característica, era excludente). Ao mesmo tempo, foi um ambiente que tornou natural as relações por meio de conversas espontâneas, olhares, gestos e atitudes, ou seja, pela sociabilidade que molda as atitudes e reações do outro. 


\section{Referências}

ABRANTES, Elizabeth Sousa. A educação feminina em São Luís (século XIX). In: COSTA, Wagner Cabral da (org.). História do Maranhão: novos estudos. São Luís: EDUFMA, 2004.

BORRALHO, José Henrique de Paula. Instituições, leitores e leitura no Maranhão em meados do século XIX. In: CASTRO, Cesar Augusto. Leitura, impressões e cultura escolar. São Luís: EDUFMA, 2010.

CASTELLANOS, Samuel Luiz Velázquez. Práticas de leitura no Maranhão na Primeira República: entre apropriações e representações. São Luís: EDUFMA, 2010.

CASTRO, C. A. Infância e trabalho no Maranhão no Maranhão Provincial: uma história da Casa dos Educandos Artífices. São Luís: EdFUNC, 2007.

CERTEAU, Michel de. A invenção do cotidiano: artes de fazer. Tradução de Ephraim Ferreira Alves. 21. ed. Petrópolis: Vozes, 2014.

CHARTIER, Roger. A história cultural entre práticas e representações. 2. ed. Lisboa: Difel, [1988].

GROGAN, Denis. A prática do serviço de referência. Brasília: Brinquet de Lemos, 2001.

LIMA, Carlos de. História do Maranhão. [S. I.: s.n.], 1981.

LOBO, Antônio. Relatório apresentado ao Sr. Governado do Estado do Maranhão Dr. João Gualberto Torreão da Costa. São Luís: typ. Frias, 1900.

LOBO, Antônio. Relatório apresentado ao Sr. Governado do Estado do Maranhão Dr. João Gualberto Torreão da Costa. São Luís: typ. Frias, 1901.

MARANHÃO. Regulamento da Biblioteca Pública de 1834. [São Luiz: s.n., 1834].

MARANHÃO. Relatório apresentado ao Sr. Governado do Estado do Maranhão Dr. João Gualberto Torreão da Costa. São Luís: typ. Frias, 1902.

MEIRELES, Mário. História do Maranhão. 3. ed. atual. Rio de Janeiro: Siciliano, 2011.

MORAES, Jomar. Guia histórico da Biblioteca Pública Benedito Leite. São Luís: FUNC, 1973.

ORTIZ, Renato. Da modernidade incompleta à modernidade mundo: sociedade e estado. Revista semestral de sociologia da UNB, Brasília, v. 15, n. 1, jan./jun. 2000.

PAIVA, Vanilda Pereira. Educação popular e educação de adultos. São Paulo: Edições Loyola, 1987. 
PERROT, Michelle. As mulheres ou os silêncios da história. Bauru: EDUSC, 2005.

RICOEUR, Paul. Ciência e ideologia. In: RICOEUR, Paul. Interpretação e ideologia. Rio de Janeiro: Francisco Alves, 1988. p. 63-95.

SAVIANI, Dermeval. Breves considerações sobre fontes para a História da educação. In.: LOMBARDI, José Claudinei; NASCIMENTO, Maria Isabel Moura (org.). Fontes, história e historiografia da educação. Campinas: Autores Associados: HISTEDBR, 2004.

SILVA, Diana Rocha da; CASTRO, Cesar Augusto. Recomeço de uma história: percurso histórico e a recriação da biblioteca pública do Maranhão na Primeira República. São Luís: EDUEMA, 2012.

SIMMEL, Georg. Questões fundamentais de sociologia: indivíduo e sociedade. Rio de Janeiro: Zahar, 2006.

VIVEIROS, Jerônimo José de. Benedito Leite: um verdadeiro republicano. 2. ed. São Paulo: Serviço de documentação, 1960.

Recebido em: 20/09/2019 Revisões requeridas em: 31/08/2020 Aprovado em: 03/11/2020

Universidade do Estado de Santa Catarina - UDESC Programa de Pós-Graduação em Educação - PPGE Revista Linhas

Volume 21 - Número 47 - Ano 2020 revistalinhas@gmail.com 